\title{
PENGGUNAAN BAHASA INDONESIA DAN BAHASA GAUL DI KALANGAN REMAJA
}

Auva Rif'at Azizah

Fakultas Ekonomi Bisnis, Universitas Pembangunan Nasional “Veteran' Yogyakarta e-mail: auvarifat.azizah@gmail.com

\begin{abstract}
Language is an important thing in human life. Through humans can be communicating. Besides language is used to convey an idea, ideas, opinions, feelings and thoughts to others. As well as a tool to develop themselves and socialize with others. A language must have a clear meaning so that when communication occurs there is no misunderstanding in its delivery. At present there are already several variations of language styles used in the community environment. The variation in language style is triggered by the development of communication technology that is developing very rapidly. The existence of this language development makes the style of language used by generations for different - different. Each generation will have the characteristics of each language style - each. The use of Indonesian that is good and right now has begun to be displaced by slang and feel accustomed to using slang.
\end{abstract}

Keywords: Indonesian language, slang, teenagers

\begin{abstract}
Abstrak: Bahasa merupakan hal yang penting dalam kehidupan manusia. Melalui manusia dapat salling berkomunikasi. Selain itu bahasa digunakan untuk menyampaikan sebuah ide, gagasan, pendapat, perasaan dan pikiran keapda kepada orang lain. Serta sebagai alat untuk mengembangkan diri dan bersosialisasi dengan yang lainnya. Suatu bahasa harus memiliki makna yang jelas agar saat terjadai komunikasi tidak terjadi sebuah kesaalaha pahaman dalam penyampaiannya. Saat ini sudah terdapat beberapa variasi gaya bahasa yang digunakan di lingkungan masyaarakat. Adanya variasi gaya bahasa dipicu oleh perkembangan teknologi komunikasi yang berkembang sangat pesat. Adanya perkembangan bahasa ini membuat gaya bahasa yang digunakan oleh generasi ke generasi berbeda - beda. Setiap generasi akan memilliki ciri khas gaya bahasanya masing - masing. Penggunaan bahasa Indonesia yang baik dan benar saat ini sudah mulai tergeser keberadaannya oleh bahasa gaul dan merasa terbiasa menggunakan bahasa gaul.
\end{abstract}

Kata Kunci: bahasa Indonesia, bahasa gaul, remaja

\section{PENDAHULUAN}

Bahasa menurut Kamus Bahasa Indonesia (2008 : 119) adalah suatu sistem lambang bunyi yang arbitrer, yang digunakan oleh anggota suatu masyarakat ununtuk bekerja sama, berinteraksi, dan mengidentifikasikan diri. Selain itu terdapat juga pendapat mengenai bahasa menurut Wibowo (2003) juga turut mengutarakan pengertian bahasa, menurutnya bahasa adalah suatu sarana perhubungan rohani yang amat penting dalam hidup bersama.

Di indonesia saat ini banyak menggunakan bahasa asing atau bahasa gaul dalam bahasa sehari - hari. Banyaknya penggunaan bahasa gaul dalam bahasa sehari - hari. Banyaknya penggunaan bahasa gaul dalam bahsa sehari - hari 
tidaklah meghilangkan penggunaan bahasa Indonesia melainkan makna dan penggunaan bahasa Indonesia yang baik, sopan dan santun dalam kehidupan sehari - hari menjadi kabur. Saat ini banyak di kalangan remaja yang menggunakan bahsa gaul dalam bahasa -sehari - hari merekan. Bahkan para remaja ini mulai menciptakan bahasa - bahasa gaul yang digunakan dikalangan mereka. Para remaja ini membuat bahasa Indonesia menjadi bahasa gaul dengan cara memplesetkan bahasa Indonesia.

Sebenarnya bahasa gaul sendiri sudah ada sejak lama, namun penyebutan istilah bahasanya yang berbeda. Dahulu bahasa gaul lebih dikenal sebagai baahasa prokem. Bahasa prokem ini popular sekitar tahun 1980 - an. Awalnya bahasa gaul digunakan oleh kelompok - kelompok tertentu saja. Hanya digunakan oleh beberapa kelompok tertentu karena tujuan awal adanya bahasa ini agar anggota kelompok tersebut saja yang mengetahui maknanya. Setiap kelompok memiliki ciri khas bahasa gaul mereka sendiri. Sehingga orang yang bukan anggota kelompok tersebut tidak mengetahui makna bahasa yang mereka gunakan dalam berkomunikasi.

Bahasa gaul dapat dikatakan sebagai kode - kode taertentu yang hanya dimengerti oleh segelintir orang saja. Bahasa gaul ini memunculkan istilah - istilah baru. Munculnya istilah istilah baru ini dikarenakan adanya modifikasi dari bahasa Indonesia yang memiliki makna yang dapat berbeda dengan makna asli bahasa Indonesia. Namun karena terlalu sering menggunakan bahasa gaul ini mengakibatkan orang - orang yang tidak berada dalam kelompok tersebutakan mengamati bahasa mereka. Mereka yang bukan anggota kelompok lama kelamaan akan mengerti bahasa yang mereka gunakan karena kerap mendengar bahasa tersebut.

\section{PENTINGNYA BAHASA INDONESIA YANG BAIK DAN BENAR}

Arum Putri (2015 : 3) berpendapat bahasa Indonesia sebagai bahasa nasional yang berfungsi sebagai alat komunikasi mempunyai peran sebagai penyampai informasi. Tidak semua warga Negara Indonesia mengerti apa makna dari bahasa Indonesia yang baik dan benar. Sesungguhnya belum tentu bahasa Indonesia yang benar itu baik dan bahasa Indonesia yang baik itu benar. Bahasa Indonesia yang baik adalah bahasa yang sesuai dengan situasi dan kondisi serta efektif dalam penyampaian maksud kepada lawan bicara. Sedangkan bahasa Indonesia yang benar adalah bahasa Indonesia yang sesuai dengan kaidah bahasa baku.

Sudah sebagai sebuah keharusan mengenai kemampuan dalam penggunaan bahasa Indonesia yang baik dan benar. Seabagai warga Negara Indonesia seharusnya mampu menggunakan bahsa Indonesia yang baik dan benar tanpa memandang dari generasi apa orang tersebut. Hal ini menjadi sebuah keharusan karena dalam kedudukannya bahasa Indonesia sebagai bahasa kebanggaan nasional, identitas nasioanal dan alat pemersatu bangsa. Bahkan kedudukan bahasa Indonesia dijelaskan pada UUD 1945 pasal 36 mengenai kedudukan bahasa 
Indonesia sebagai bahasa remi kenegaraan, pengantar dalam pendidikan alat penghubung tingkat nasional dan alat pengembangan kebudayaan dan IPTEK.

Berdasarkan kedudukan bahasa Indonesia maka secara otomatis bahasa Indonesia ini harus diigunakan dalam kegiatan yang bersifat formal maupun nonformal. Namun kenyataannya yang terjadi sekarang ini penggunaan bahasa Indonesia dikalangan masyarakat sudah bercampur dengan bahasa gaul.

\section{FENOMENA PENGGUNAAN BAHASA GAUL}

Menurut Mulyana (dalam Sari 2015 : 2 ), bahasa gaul adalah sejumlah kata atau istilah yang mempunyai arti yang khusus, unik, menyimpang atau bahkan bertentangan dengan arti yang lazim ketika digunakan oleh orang-orang dari subkultur tertentu. Selain bahasa gaul dahulu masyarakat popular dengan bahasa prokem. Menururt Pusat Bahasa dan Sastra (dalam Hilaliyah 2010 : 2) Bahasa prokem biasa juga disebut sebagai bahasa sandi, yaitu bahasa yang dipakai dan digemari oleh kalangan remaja tertentu

Bahasa gaul merupakan salah satu cabang bahasa dari bahasa Indonesia. Bahasa gaul umumnya mulai muncul di kalangan masyarakat pada tahun 1980 an. Pada tahun 1980 - an bahasa gaul lebih dikenal dengan bahasa prokem. Bahasa prokem saat itu digunakan oleh kalangan pergaulan preman. Penggunaan bahasa prokem ini dapat dikatakan sebagai kode yang digunakan oleh kelompok tertentu. Dapat dikatakan sebagai kode karena makna dari bahasa prokem setiap kelompok dapat berbeda - beda. Makna dari bahasa tersebut hanya diketahui oleh anggota kelompok tersebut saja. Pada awalnya penggunan bahsa prokem ini bertujuan untuk merahasiakan isi obrolan dari kelompok tertentu.

Penggunaan bahasa prokem oleh preman saat itu tidak digunakan pada situasi dan tempat yang khusus, melainkan pada situasi dan tempat yang umum. Terlalu seringnya menggunakan bahasa prokem ini menjadikan orang awam yang bukan anggota kelompok tersebut lama kelamaan akan mengerti makna dari bahasa sandi tersebut. Pada akhirnya penggunaan bahasa prokem ini tidak hanya digunakan oleh kalangan anggota kelompok tertentu saja. Namun orang awam yang bukan anggota dari kelompok tersebut juga mulai menggunakan bahasa prokem dalam kehidupan sehari - hari mereka. Oleh karena itu makna dari bahasa prokem tidak lagi menjadi bahasa yang memiliki makna rahasia.

Seiring berjalannya waktu, sejalan dengan adanya perkembangan teknologi komunikasi menyebabkan perkembangan bahasa menjadi pesat. Selain perkembangan teknologo komunikasi ini mendorong perkembangan bahasa, namun juga menimbulkan masalah mengenai keberadaan bahasa Indonesia yang baik dan benar. Hal ini didukung dengan mulai munculnya situs jejaring social di dunia maya yang digunakan oleh masyarakat. Penggunaan jejaring social ini memudahkan seseorang dalam mengetahui perkembangan bahsa yang ada.

Perkembangan bahasa dalam dunia maya ini dapat memunculkan berbagai macam gaya bahasa baru dalam kehidupaan masyarakat. Perkembangan bahasa 
ini menjadi pesat karena dalam mengakses situs jejaring social tidak hanya terbatas pada pengguna dalam negeri, namun juga luar negeri. Interaksi antar Negara inilah yang membuat perkembangan gaya bahasa menjadi pesat. Dengan adanya perkembangan bahasa ini dapat membuat gaya bahasa Indonesia menjadi bervariasi. Pada awal tahun 2000 istilah bahasa gaul mulai dikenal dan popular terutama dikalangan remaja.

Menurut Femi Oktaviani (2014 : 5) Remaja merupakan bagian dari masyarakat yang membentuk kelompok kecil (subkultur) yang terbentuk oleh kesamaan umur. Subkultur ini mengembangkan sistem komunikasi sendiri demi meningkatkan efisiensi. Mereka juga membentuk budaya sendiri sesuai dengan nilai, norma, dan cara berpikirnya.

Saat ini penggunaan bahasa Indonesia yang baik dan benar dalam kehidupan sehari - hari sudah mulai bergeser digantikan oleh bahasa gaul. Bahasa gaul jika digunakan dalam situasi nonformal akan dapat dipahami, namun sangat tidak tepat jika penggunaan bahasa gaul ini digunakan dalam situasi yang formal. Bahasa gaul banyak digunakan oleh kalangan remaja. Banyaknya pengguna remaja dipicu oleh gengsi dalam diri mereka karena jika tidak mengetahui, mengerti dan menggukan bahasa gaul maka remaja tersebut akan dianggap ketinggalan jaman oleh reamja lain.

Fenomena penggunaan bahasa gaul tidak hanya hasil dari modifikasi bahasa Indonesia namun juga terdapat modifikasi bari bahasa lain. Bahasa gaul sendiri tidak hanya hasil dari modifikasi suatu bahasa namun juga dapat berupa bahasa bahasa yang sedang popupler digunakan oleh khalayak ramai. Adapun tabel berikut ini memaparkan bahasa gaul yang merupakan hasil dari modifikasi bahasa baku bahasa Indonesia yang baik dan benar. Menurut Nurhasanah (dalam Swandy 2017 : 4) Bahasa gaul adalah gaya bahasa yang merupakan perkembangan atau modifikasi dari berbagai macam bahasa, termasuk bahasa Indonesia sehingga bahasa gaul tidak memiliki sebuah struktur gaya bahasa yang pasti.

\begin{tabular}{c|c}
\hline Bahasa Gaul & Ejaan PUEBI \\
\hline Santuy & Santai \\
\hline Sans & Gemas \\
\hline Gemay & Bias \\
\hline Sabi & Sikat \\
\hline Takis & Kesal \\
\hline Kezel & Yuk \\
\hline Kuy & Hakiki \\
\hline Hqq & Keras \\
\hline Kerad & Terciduk \\
\hline Tercyduk & Mantap betul \\
\hline Mantul & Jalur pribadi \\
\hline Japri & Sampah abis \\
\hline Sampis & Negara berkembang \\
\hline Negara ber-flower
\end{tabular}


Dapat dilihat pada tabel jika penggunaan bahasa gaul merupakan hasil modifikasi dari bahasa baku. Penggunaan bahasa gaul diatas dalam praktiknya sering digunakan dalam obrolan sehari - hari atau pada saat saling mengirim pesan. Selain kata yang terdapat pada tabel masih terdapat banyak jenis bahasa gaul yang digunakan di kalangan masyarakat. Misalnya seperti pencampuran penggunaan bahasa Indonesia dan bahasa inggris yang daling dikombinasikan. Dapat juga berupa singkatan kata yang unik dari penggabungan beberapa kata bahasa baku. Selain itu juga bisa berupa bahasa - bahasa daerah yang memiliki pelafalan dan penulisan yang unik.

\section{PENGARUH PENGGUNAAN BAHASA GAUL TERHADAP BAHASA INDONESIA}

Menurut Arum Putri (2015 : 5) penyebab banyaknya penggunaan bahasa gaul saat ini karena kurangnya rasa cinta mereka terhadap bahasa Indonesia sebgai bahasa nasional. Saat ini sejalan dengan perkembangan zaman semakin terlihat pengaruh yang diberikan oleh bahasa gaul terhadap penggunaan bahsa Indonesia yang baik dan benar dalam penggunan tatanan bahasanya. Penggunaan bahasa gaul paada kalangan remaja membawa pengaruh yang kurang baik terhadap perkembangan bahasa Indonesia sebagai indentitas nasional. Saat ini banyak di kalangan masyarakat yang sudah memakai bahasa gaul dalam kehidupan sehari - hari mereka. Seolah - olah tidak memahami bahwa bahasa Indonesia sebagai bahasa nasional. Bahkan pengguna bahasa gaul merambah ke ranah kalangan anak remaja. Seharusnya sebagai warga Negara Indonesia menghindaari pemakaian bahasa gaul yang sangat banyak digunakan di masyarakat.

Terlalu banyaknya pengguna bahasa gaul dikalangan remaja membuat prihatin bangsa ini. Para generasi muda yang diharapkan dapat memajukan bangsa dari segala aspek inilah yang harus menjadi perbaikan bersama. Solusi yang dapat diberikan yaitu dengan menanamkan kecintaan dalam diri mereka terhadap bangsa Indonesia terutama dalam penggunaan bahasa Indonesia.

Dalam hubungan internasional, bahasa Indonesia merupakan perwujudan dari bahasa Indonesia sebagai bahasa nasional. Munculnya bahasa gaul dalam lingkungan masyarakat, membawa pengaruh pada bahasa Indonesia. Arum Putri (2015 : 5) mengemukakan pendapatnya mengenai pengaruh yang ditimbulkan oleh bahasa gaul sebagai berikut : Pertama, eksistensi keberadaan bahasa dengan bahasa gaul. Adanya pengaruh arus perkembangan tekonoligi dan komunikasi dicerminkan pada perilaku masyarakat yang mulai meninggalkan bahasa Indonesia yang baik dan benar. Saat ini dalam lingkungan masyaarakat mulai terbiasa menggunakan bahaasa gaul. Hal ini di perparah dengan fenomena para generasi muda lebih tertarik untuk mempelajarii bahasa asing daripada menguasai bahasanya sendiri. Dalam kondisi seperti ini, sangat perlu untuk memberikan pembinaan dan pemupukan mengenai bahasa Indonesia sejak dini kepada 
generasi muda agar mereka tidak ikut menggunakan bahasa gaul. Pengaruh arus globalisasi dalam identitas bangsa tercermin pada perilaku masyarakat yang mulai meninggalkan bahasa Indonesia.

Kedua, menurunnya dejarat bahasa Indonesia. Dalam perkembangan sejarah pertumbuhan bahasa, pertumbuhan bahasa asing memiliki perkembangan yang lebih maju. Seperti yang ada di sekitar kita perkembangan IPTEK saat ini dikuasai oleh bangsa - bangsa barat. Maka jika pada produk IPTEK yang mereka hasilnya disertai dengan penggunaan bahasa asing maka itu adalah suatu hal yang wajar. Selain itu bahasa gaul begitu mudah untuk digunakan berkomunikasi dan hanya orang tertentu yang mengerti arti dari bahasa gaul, maka remaja lebih memilih untuk menggunakan bahasa gaul sebagai bahasa sehari-hari. Sehingga bahasa Indonesia semakin pudar bahkan dianggap kuno di mata remaja dan juga menyebabkan turunnya derajat bahasa Indonesia.

Selain itu Beta Puspa (2015 : 5) juga mengungkapkan bahwa terdapat pengaruh yang posistif dan negatif dari bahasa gaul sebagai berikut : dampak positif ini dapat dilihat bawa penggunaan bahahasa gaul banyak digunakan di kalangan remaja. Namun bila penggunaan bahasa gaul ini digunakan pada situasi yang tepat akan memberikan manfaat mengenai inovasi bahasa yang muncul nantinya.

Sedangkan dampak negative, penggunaan bahasa gaul dapat mempersulit pengguna bahasa Indonesia dengan baik dan benar. Padahal di sekolah atau di tempat kerja, kita diharuskan untuk selalu menggunakan bahasa Indonesia yang baik dan benar. Bahasa gaul dapat mengganggu siapapun yang membaca dan mendengar kata-kata yang termaksud di dalamnya. Karena, tidak semua orang mengerti akan maksud dari kata-kata gaul tersebut. Terlebih lagi dalam bentuk tulisan, sangat memusingkan dan memerlukan waktu yang lebih banyak untuk memahaminya. Bahasa gaul dapat mempersulit penggunanya dalam berkomunikasi dengan orang lain dalam acara yang formal.

\section{SIMPULAN}

Masyarakat Indonesia saat ini banyak yang menggunakan bahasa gaul dan singkatan - singkatan dala kegiatan sehari - hari merupakan bentuk penyimpangan dari penggunaan bahasa Indonesia yang baik dan benar. Adannya penyimpangan ini dapat menghambat pertumbuhan dan perkembangan bahasa Indonesia. Luntur atau hilangnnya penggunaan bahasa Indonesia dikarenakan kurangnya kesadaaran dalam diri untuk mencintai dan menggunakan bahasa Indonesia di negeri sendiri. Hal ini terkadang diperparah oleh maraknya dunia artis yang menggunakn bahasa gaul di media massa dan elektronik. 


\section{DAFTAR PUSTAKA}

Wibowo, Wahyu. 2003. Manajemen Bahasa. Jakarta: Gramedia

Tim Penyusun. 2008. Kamus Bahasa Indonesia. Jakarta: Pusat Bahasa

Rahayu, Arum Putri. 2015. "Menumbuhkan Bahasa Indonesia yang Baik dan Benar dalam Pendidikan dan Pengajaran". Dalam Jurnal: Paradigma, Volume 2, Nomor 1, Halaman 1-15.

Swandy, Eduardus. 2017. "Bahasa Gaul Remaja dalam Media Social Facebook". Dalam Jurnal: Bastra volume 1 nomor 4, halaman 1-4.

Oktaviani, Femi. 2014. "Hubungan Antara Penggunaan Bahasa Gaul dengan Keterbukaan Komunikasi di Kalangan Siswa". Dalam Jurnal IImu Komunikasi. JIKA. Volume.1 No.1, halaman 4-5.

Sari, Beta Puspa. 2015. “Dampak Penggunaan Bahasa Gaul di Kalangan Remaja Terhadap Bahasa Indonesia". Dalam Prosiding Seminar Nasional Bulan Bahasa UNIB 2015, halaman 2-5.

Hilaliyah, Hilda. 2010. "Maraknya Penggunaan Bahasa Gaul di Kalangan Pelajar Sekolah Menengah Atas". Dalam Jurnal: Dieksis Vol. 02 No. 01 Januari - Maret 2010, halaman 2. 